\title{
A Ótica do Professor Formador sobre a Integração das Tecnologias à Licenciatura em Matemática
}

\section{The Perspective of the Teacher Educator on the Integration of Technologies with Mathematics Licensure}

\author{
Elivelton Serafim Silva ${ }^{1}$ \\ Silvanio de Andrade ${ }^{2}$ \\ 'Universidade de São Paulo (USP), Faculdade de Educação, São Paulo, SP, Brasil. \\ Autor Correspondente: elivelton@usp.br \\ ${ }^{2}$ Universidade Estadual da Paraíba (UEPB), Campina Grande, PB, Brasil.
}

Resumo: Mediante pesquisa qualitativa, analisamos a percepção de professores formadores ligados ao campo da educação matemática a respeito da integração das tecnologias digitais como uma ferramenta pedagógica na licenciatura em matemática. Os dados foram construídos por meio de entrevistas feitas com seis professores formadores de diferentes Estados brasileiros. Para análise dos dados utilizamos o Discurso do Sujeito Coletivo. Dos resultados obtidos, os professores formadores defendem que durante a formação inicial do professor de matemática seja inserida a maior quantidade possível de ferramentas tecnológicas. Inferem que, na organização da disciplina, constem momentos de estudos teóricos a respeito do uso didático das tecnologias na escola básica, assim como o desenvolvimento de atividades práticas utilizando as ferramentas tecnológicas. Conclui-se que a organização da prática dos formadores entrevistados aponta para o estudo teórico como algo indispensável, porém, deve ser destinado mais tempo para o desenvolvimento de atividades práticas que integrem docência e novas tecnologias digitais.

Palavras-chave: Ensino de matemática; Formação inicial do professor; Informática e educação; Discurso do sujeito coletivo.

Abstract: Through qualitative research, we analyzed the perception of educators of mathematics teachers regarding the integration of digital technologies as a pedagogical tool with licensure in mathematics. The data were gathered through interviews with six teacher educators from different Brazilian states. The Discourse of the Collective Subject was used for data analysis. According to the results obtained, the teacher educators argue that during the pre-service education of mathematics teachers, as many technological tools as possible should be introduced. They infer that, in the organization of curricular components, there should be moments for theoretical studies about the didactic use of technologies in basic education, as well as the development of practical activities using technological tools. The conclusion is that the practical experience of the interviewed teacher educators points to theoretical study as something indispensable; however, more time should be devoted to the development of practical activities that integrate teaching and new digital technologies.

Keywords: Mathematics teaching; Pre-service teacher education; Informatics and education; Collective subject discourse.

Recebido em: 29/11/2019

Aprovado em: 18/10/2020 


\section{Introdução}

A rede mundial de computadores conectou diferentes partes do mundo de modo inédito, facilitando a circulação de informações e fomentando as relações humanas. Nesse sentido, as novas tecnologias de informação e comunicação revolucionaram as relações e organizações sociais. Essas transformações pelas quais a sociedade tem passado desafiam organizações e instituições, pois apontam para a necessidade de mudanças de propósitos, estrutura e procedimentos.

Dessa maneira, é de suma importância que a formação inicial do professor de matemática também contemple a discussão a respeito do uso de tecnologias e prepare o futuro professor para integrar as tecnologias à sua prática escolar, no sentido de que elas colaborem para a construção dos saberes matemáticos, bem como forneçam bases para uma atuação de mediação que favoreça o gerenciamento de informações e o aprofundamento do conhecimento nessa formação inicial do professor.

Nesse sentido, Hargreaves (2004, p. 17) afirma que:

Vivemos em uma economia do conhecimento, em uma sociedade do conhecimento. As economias do conhecimento são estimuladas e movidas pela criatividade e pela inventibilidade, as escolas da sociedade do conhecimento precisam gerar essas qualidades, caso contrário, seus povos e suas nações ficarão para trás.

A inserção das tecnologias no âmbito dos cursos de licenciatura em matemática pode contribuir para a formação de um professor capaz de promover um ensino reflexivo que estimule o desenvolvimento do raciocínio lógico, criatividade, espírito de investigação e exploração, aspectos esses essenciais na formação do cidadão para a sociedade atual.

Assim, elaboramos o presente trabalho com o objetivo de analisar a percepção de professores formadores ligados ao campo da educação matemática a respeito da integração das tecnologias digitais como uma ferramenta pedagógica na licenciatura em matemática.

\section{Metodologia da Pesquisa}

Optamos por realizar uma pesquisa qualitativa e utilizar a entrevista semiestruturada como ferramenta para o levantamento de dados, por entender ser esse o instrumento mais indicado para alcançar nosso objetivo de pesquisa, tendo em vista que a entrevista propicia um maior esclarecimento das respostas dadas a cada pergunta, assim como a captação de informação via tom de voz, expressão facial, detalhes, que são perdidos quando utilizamos o questionário.

Assim, nosso universo é composto por seis professores formadores: três que atuam no Estado da Paraíba, dois no Estado de São Paulo e um no Estado de Mato Grosso do Sul.

Todos os participantes nos concederam entrevistas, as quais foram gravadas em áudio e, posteriormente, transcritas para análise. É importante salientar que procuramos oferecer as mesmas condições de resposta, tanto aos formadores que foram entrevistados presencialmente quanto aos que foram entrevistados à distância mediante chamada de vídeo. 
Em todas as entrevistas, os professores não tiveram acesso ao roteiro de perguntas com antecedência, cada um tomou conhecimento de cada pergunta ao passo que eram questionados e, após a conclusão de uma resposta, prosseguíamos com a próxima pergunta.

Elaboramos sete perguntas direcionadas à prática do professor formador a fim de entender as percepções dele a respeito de alguns aspectos da sua prática, conforme listamos a seguir:

1. Quais ações você julga importantes na formação inicial do professor de matemática no que diz respeito ao uso das tecnologias?

2. Para você, quais as características da prática de um bom professor da área de tecnologia aplicada ao ensino de matemática?

3. O que você julga indispensável no ensino da disciplina de tecnologia aplicada à educação matemática que você ministra?

4. Quais são os obstáculos que você enfrenta para ministrar essa disciplina em cursos de licenciatura em matemática?

5. Didaticamente, qual a melhor maneira de ensinar essa disciplina num curso de licenciatura em matemática? Você tem alguma proposta nessa direção?

6. Qual a importância da disciplina de tecnologia aplicada à educação matemática que você ministra para formação de um profissional com pensamento crítico e autônomo?

7. A seu ver, que tipo de atividade é importante trabalhar nessa disciplina e de que maneira ela poderia colaborar com a prática da sala de aula do futuro professor de matemática na educação básica?

A primeira pergunta foi elaborada com o intuito de entender a percepção do professor formador a respeito do papel da disciplina de tecnologias aplicada à educação matemática, a qual ministra ou já ministrou na formação inicial do professor de matemática. As perguntas dois, três, cinco e sete foram elaboradas com o objetivo de entender como o professor organiza a sua prática na disciplina referida. A quarta pergunta teve o intuito de entender o que dificulta o trabalho do professor em sala de aula, pois, para que o professor efetive sua prática, ele depende de inúmeras variáveis, as quais não podem deixar de ser consideradas. Já a sexta pergunta vislumbra entender a proximidade entre o formador e a realidade da formação crítica social dentro da perspectiva das tecnologias.

Como ferramenta de análise de dados, optamos por utilizar a metodologia do Discurso do Sujeito Coletivo (DSC) desenvolvida nos últimos anos por Lefèvre e Lefèvre $(2005,2010)$ e que tem, gradativamente, ganhado espaço como metodologia de análise em pesquisas qualitativas.

Essa metodologia padroniza e sistematiza procedimentos viabilizando agregar os discursos individuais, ao dar voz à coletividade como se fosse um só individuo, partindo da materialização do discurso, em nosso caso, da transcrição de entrevistas.

\section{Descrição e Análise de Dados}

O acesso à informação é uma marca de nossa sociedade. Sendo assim, é relevante a preocupação de que a escola agregue as tecnologias ao seu cotidiano, não apenas como forma de tecnologizar o ensino bancário baseado na cópia e repetição, mas, também, para que o ensino seja repensado a partir desses novos paradigmas sociais. 
Nesse sentido, entendemos que a formação inicial do professor é uma ferramenta importantíssima para que haja uma reconfiguração do ensino escolar. Portanto, nesta seção, discutiremos as percepções de seis professores formadores que ministram, ou ministraram disciplinas de educação matemática relacionadas ao uso de tecnologias em cursos de licenciatura em matemática espalhados pelo Brasil.

\section{O papel da abordagem pedagógica das tecnologias na Licenciatura em Matemática}

Unanimemente, os professores formadores apontaram a necessidade de que o aluno da licenciatura tenha contato com as ferramentas tecnológicas, observando aspectos teóricos mediante leitura de artigos acadêmicos e discussão das ideias de autores. Também enfatizaram o aspecto prático voltado à utilização da ferramenta no ambiente da sala ou laboratório da universidade, assim como ações práticas voltadas para o estágio supervisionado, no qual os futuros professores estariam inseridos no contexto escolar, enfrentando dificuldades reais. Nessa perspectiva, os formadores indicam que a formação tecnológica oferecida aos professores de matemática durante sua graduação precisa integrar estudos teóricos e ações práticas.

Eles sugerem que durante a graduação haja uma formação tecnológica instrumental, para que, no futuro, o graduando possa usar as tecnologias a fim de gerenciar suas atividades docentes, por exemplo, no preparo de aulas, elaboração de atividades, provas e gerenciamento de notas. A indicação dos formadores está em harmonia com a pesquisa de Ponte, Oliveira e Varandas (2002): nela, os pesquisadores defendem que durante a formação inicial haja a introdução de softwares e ferramentas utilitárias que auxiliarão no exercício da docência.

Não há um consenso a respeito de como abordar o uso pedagógico das tecnologias durante a licenciatura, entretanto, os professores apontam que a abordagem tecnológica, como ferramenta para o ensino, deve perpassar toda a formação inicial. Nesse sentido, alguns apoiam a necessidade de uma disciplina específica dentro do campo da Educação Matemática que trate do uso de tecnologia, enquanto outros apoiam que essa abordagem seja agregada às diversas disciplinas que compõem o currículo pedagógico da formação inicial, como disciplinas de práticas de ensino, estágio ou metodologia de ensino da matemática. Eles afirmam que:

Outro aspecto é que dentro do próprio curso a tecnologia seja abordada com dois enfoques. Um deles é a tecnologia pra que o aluno use de forma complementar os seus estudos, para compreender disciplinas de cálculo, por exemplo. E o outro enfoque é a tecnologia como ferramenta para ensinar matemática. Uma das grandes questões é que na hora de estudar cálculo e geometria, seria fundamental esse professor também estar usando tecnologia para o aluno aprender, porque daí o aluno teria vivenciado o processo de aprendizagem com tecnologia [Discurso do Sujeito Coletivo - Ideia Central: deve preparar o professor para usar os softwares de maneira utilitária e como recurso para o ensino, 2019].

Segundo os professores formadores, as tecnologias devem ser integradas à prática dos formadores responsáveis por disciplinas específicas da matemática para que os alunos possam vivenciar o processo de construção de conhecimento via uso de tecnologias. 
Os entrevistados também destacam que o professor formador deve incentivar o futuro professor a desenvolver o hábito de refletir de uma maneira que exerça julgamento técnico e didático frente ao uso das ferramentas tecnológicas disponíveis.

\section{Como o professor organiza sua prática}

Ao pensarmos no ensino via tecnologias, dentro do rol das competências técnicas, além do domínio da matemática, segundo os professores, também é de suma importância que haja o domínio da ferramenta tecnológica com a qual o professor se dispõe a trabalhar.

Outro aspecto levantado pelos entrevistados é que os sujeitos da formação inicial (professor formador e alunos) tenham compreensão de que o uso de tecnologias "não é para deixar a aula 'bonitinha', ou seja, a tecnologia é algo para 'pensar com' e não para ilustrar a aula" (Discurso do Sujeito Coletivo - Ideia Central: dimensão técnica, 2019). Nesse sentido, Costa e Prado (2015, p. 102) defendem que as tecnologias sejam integradas ao ensino de maneira que sejam exploradas adequadamente para que o futuro professor possa "raciocinar com", "criar com" e "ensinar com", ou seja, a ferramenta tecnológica deve ser usada para que, através de sua exploração, haja a construção do conhecimento.

Dessa forma, os professores apontam que:

O aluno precisa pensar também nessa parte científica, que é a parte que dá um embasamento de como utilizar as tecnologias dentro do conhecimento matemático que vai ser trabalhado em sala de aula. Ele [o professor formador] tem que pensar em fazer com que o aluno entenda o uso daquela ferramenta, a relevância daquela ferramenta específica ou das ferramentas que ele trabalha. Ele tem que saber estruturar o programa da disciplina de forma que, com o passar da disciplina, o aluno vá adquirindo mais habilidade. Ele tem também que saber envolver a turma de forma que desperte o interesse para aquele tipo de atividade, porque nem todos os alunos são adeptos da tecnologia. Então, ele tem que mostrar essa possibilidade de trabalhar com tecnologia e estar pronto para o inusitado. Porque essa é uma Disciplina que não exige só o trabalho do professor, o planejamento do professor. Então ele tem que sempre ter um plano 'B'. [Discurso do Sujeito Coletivo - Ideia Central: dimensão estética, 2019].

Além do domínio técnico, segundo os entrevistados, o professor formador precisa dominar os elementos estéticos que compreendem a organização da aula. Caso um sujeito domine bem as ferramentas tecnológicas, ou mesmo os conceitos matemáticos, isso não implica dizer, necessariamente, que ele é um bom professor de matemática. Além do domínio técnico, é preciso conhecer maneiras de socializar esse conhecimento e o direcionar para a construção autônoma de conhecimentos.

Os formadores entrevistados destacam a necessidade de estruturar a exploração das ferramentas e conceitos matemáticos, de modo que a exploração parta do simples para o complexo. Eles defendem que as atividades elaboradas para exploração sejam interessantes e apresentem um nível de dificuldade adequado ao nível da turma, para que o professor em formação se envolva na exploração da ferramenta.

Segundo o relato dos entrevistados, é comum que, durante as aulas, surjam problemas com a rede de internet, hardware ou software. Nesse sentido, destacam que o professor formador precisa ser capaz de planejar as aulas de modo a minimizar as adversidades, além de incluir em seu planejamento outras possibilidades para prosseguir a aula, caso surja um problema sem solução imediata. 
O coletivo expõe a preocupação dos professores formadores no que diz respeito ao uso de modelos representados pelo material didático manipulável ou por ferramentas tecnológicas, pois o significado que o aluno atribui ao modelo pode levá-lo a construir um conceito matemático errado ou a uma repetição mecânica e sem significado.

Desse modo, os entrevistados apontam a necessidade de trabalhar a análise crítica das diversas ferramentas tecnológicas (softwares utilitários, softwares educacionais, ferramentas de busca, internet, redes sociais, calculadora, entre outros), de modo que os futuros professores desenvolvam o domínio técnico e didático para que o uso das ferramentas tecnológicas seja potencializado. Segundo eles:

\begin{abstract}
É indispensável você fazer uma discussão do potencial da tecnologia para o ensino, como utilizá-la e tentar que seja sempre uma postura construcionista. Têm que ter a parte de conhecimento matemático, porque, às vezes, a gente se dedica muito à parte técnica da informática e se distancia um pouco do conteúdo, e o principal é o conteúdo. [...] precisa ter um cunho teórico e outro mais prático, sempre ressaltando que a máquina não faz tudo, a tecnologia não faz tudo. Ela potencializa uma série de situações, mas é extremamente importante e cada vez mais complexa a figura do professor. [Discurso do Sujeito Coletivo - Ideia Central: professor mediador, 2019].
\end{abstract}

Outro aspecto suscitado é a importância de o professor formador "conhecer a realidade da educação básica", a necessidade de contextualização da abordagem tecnológica durante a formação inicial. De acordo com os formadores entrevistados, para conhecer a realidade da escola básica, a observação não é suficiente. Para eles, a construção de parcerias, em que as ideias e experiências do professor da educação básica sejam consideradas e debatidas, é de extrema importância.

As atividades de investigação e resolução de problemas também foram sugeridas pelos entrevistados como essenciais para a disciplina. Esse tipo de atividade foi mencionado de maneira unânime, direta ou indiretamente, talvez por possibilitar um maior envolvimento ativo do aluno com a aprendizagem, o que pode facilitar a construção de conhecimento.

Para os entrevistados:

Do ponto de vista didático, que o professor vincule aquilo que está fazendo na Disciplina com o que realmente o licenciando vai precisar para a sala de aula. Isso aí é fundamental. Nessa perspectiva, seria importante uma parte mais teórica, depois, uma parte mais prática, sempre gerando discussões sobre as concepções do uso de tecnologia, envolvendo os grupos de alunos nessa discussão. Poderíamos, também, utilizar uma metodologia baseada na investigação matemática ou na resolução de problemas. Ou mesmo que os alunos pensem no uso de determinadas tecnologias e proponham um projeto a ser desenvolvido. Aí, a partir do desenvolvimento de projetos, eles vão aprendendo a lidar com a tecnologia, tanto naquilo que eles mesmos estão propondo nos grupos, quanto no que os demais estão fazendo.

[Discurso do Sujeito Coletivo - Ideia Central: orientação didática, 2019].

É importante destacar que as atividades envolvendo as ferramentas tecnológicas surgem como instrumentos para serem usados livre e criativamente por professores e alunos na realização das mais diversas atividades, especialmente as atividades de projetos e investigação, por proporcionarem ao aluno um protagonismo na aprendizagem. Além disso, as tecnologias da informação e comunicação podem ser usadas como recurso para investigação. 


\title{
Entraves que dificultam a prática
}

Agregar as tecnologias ao ensino é algo importante, necessário, mas algo que ainda não é consolidado na totalidade de nosso país. Essa consolidação é impedida não apenas pelos desafios pedagógicos, mas, também, pela falta de sólidos investimentos do governo, tanto para o aperfeiçoamento pedagógico do professor, quanto em melhoras estruturais, pois, como afirma Corrêa (2000, p. 49), na lógica neoliberal, os investimentos divulgados na mídia são reduzidos e mal direcionados para setores estratégicos, causando aparentes melhoras; entretanto, promovem a manutenção do sistema.

Outro grande desafio, provocado, em parte, pela competição capitalista em busca de lucros individuais, consiste no desenvolvimento de softwares pagos ou que são executáveis em determinado sistema operacional. Um grande problema enfrentado nas Instituições de Ensino Superior brasileiras é que o sistema operacional mais popular em nosso país é o Windows, da empresa Microsoft. Entretanto, a aquisição e manutenção das atualizações desse sistema demandam recursos de que muitas instituições não dispõem. Por isso, optam por utilizarem o sistema operacional Linux, por oferecer, de maneira geral, um melhor custo benefício. Contudo, essa dualidade de sistemas tem gerado muitos problemas de compatibilidade de arquivos, para os quais o professor necessita estar preparado a fim de contorná-los.

Segundo os entrevistados:

\begin{abstract}
Uma das dificuldades é o uso de laboratórios. A gente não tem cada aluno com um computador, seria muito bom. Parece que todo mundo tem celular, todo mundo tem, mas na hora ' $H$ ' que você vai precisar para uma aula, você não tem os equipamentos ali na sua sala. No momento em que você vai pôr a 'mão na massa', muitas vezes, os laboratórios estão priorizando os alunos de outros cursos. [...] Outro obstáculo seria a questão da falta de equipamento em casa para dar continuidade aquela discussão que inicia na universidade. E, por fim, apontamos a falta de conhecimento sobre lidar com determinadas tecnologias. [Discurso do Sujeito Coletivo - Ideia Central: dificuldades técnicas, 2019].
\end{abstract}

Partindo para as dificuldades pedagógicas, os professores apontam a falta de interesse dos alunos pela disciplina. Esse desinteresse pode ser causado por fatores diversos, como, por exemplo, a abordagem de tópicos da matemática que não são ensinados na educação básica.

Para os professores formadores:

\begin{abstract}
A maior dificuldade está na resistência ao uso de tecnologia para ensinar matemática. É lidar, muitas vezes, com uma turma de alunos com interesses e habilidades distintas, onde alguns têm habilidades $e$ outros não, alguns têm computador em casa, outros não. [...] Outro fator seria essa questão do conceito matemático, essa dificuldade que os alunos têm com a matemática do ensino básico. [...] Outro fator é que nós estamos habituados em dar a mesma aula para todo mundo, a mesma atividade desenvolvida para todo mundo, ao mesmo tempo, em sala de aula. Só que, quando você coloca uma situaçãoproblema com tecnologia, as dificuldades são diferentes e o atendimento tem que ser, mais ou menos, um atendimento individual. Então, quando você está num laboratório de informática, você precisa estar mediando os alunos à máquina, isso é difícil. [Discurso do Sujeito Coletivo - Ideia Central: dificuldades pedagógicas, 2019].
\end{abstract}

A criação de roteiros de aula foi indicada como outra dificuldade. Como não existem muitos modelos prontos, o professor precisa desenvolvê-los. 


\section{Tecnologias e a formação crítica cidadã}

A formação de um cidadão crítico é algo fundamental para a emancipação humana. Por um lado, o desenvolvimento crescente da ciência e tecnologia liberta os agentes sociais dos trabalhos braçais humanos exaustivos; por outro lado, outras perspectivas exigem o desenvolvimento da crítica, inventividade e criatividade, como sugerem os trabalhos de Giroux (1997), Hargreaves (2004), Justice e Tenore (2018), Phelan e Sumsion (2008). Nesse ínterim, o papel do professor como intelectual transformador torna-se fundamental.

Nesse âmbito, a formação tecnológica do professor de matemática também deve contribuir para a educação de intelectuais transformadores, promovendo a aquisição de conhecimentos específicos, instigando o senso crítico do futuro professor para atuar como agente ativo na conceitualização, planejamento e organização curricular dos processos escolares, incluindo o uso de tecnologias e utilizando-as para tratar das relações de poder, como opressão de grupos minoritários, ética e valores sociais, instigando o aluno à necessidade da participação na luta para superar as injustiças econômicas, políticas e sociais.

Autores como Diniz-Pereira (2011), Kincheloe (1997) e Zeichner (2011) defendem que, para a formação de um professor intelectual e transformador, faz-se necessário um ensino reflexivo dando um destaque ao uso da pesquisa-ação nas práticas da formação inicial. Esse tipo de prática opõe-se a uma sequência mecânica de passos, levando o futuro professor a envolver-se em um ciclo autorreflexivo de planejar, refletir, agir, observar e rever o planejamento de maneira cíclica.

Essa formação reflexiva pautada nos aspectos técnicos, éticos, políticos e sociais, baseada em fundamentos morais e numa crítica política, converge para que intelectuais transformadores atuem conforme aponta Giroux (1997, p. 163):

\footnotetext{
Desta maneira, eles devem se manifestar contra as injustiças econômicas, políticas e sociais dentro e fora das escolas. Ao mesmo tempo, eles devem trabalhar para criar as condições que dêem aos estudantes a oportunidade de tornarem-se cidadãos que tenham o conhecimento e a coragem para mudar a fim de que o desespero não seja convincente e a esperança seja viável.
}

A formação de um professor de matemática como um intelectual transformador esbarra, primeiramente, no fato de a licenciatura em matemática ser concebida como um curso na área das ciências exatas. Área que valoriza os procedimentos técnicos e hipotético-dedutivos, necessários à construção de seus conceitos característicos. Portanto, para muitos, uma formação reflexiva soa como um ataque às bases da matemática e muitos a interpretam como uma maneira de os alunos aprenderem "menos matemática".

Nesse sentido, a disciplina de educação matemática aplicada ao uso de tecnologias pode oferecer sua contribuição para a formação de um professor intelectual transformador, tendo como premissas: utilização das tecnologias para a construção de conhecimentos matemáticos; possibilidades pedagógicas que esse tipo de ferramenta oferece ao ensino-aprendizagem; constituição de um espaço que instigue a reflexão tanto sobre questões educacionais voltadas ao contexto escolar quanto no que se refere a questões sociais diversas. 
Durante as entrevistas, no que diz respeito à formação crítica do professor de matemática foi mencionado o seguinte: "Essa questão eu acho que está mais longe da nossa sala de aula quando nós estamos pensando tecnologia [...]" [Discurso do Sujeito Coletivo - Ideia Central: Para refletir criticamente sobre os dados fornecidos pelas TIC, 2019], revelando a fragilidade das ações desenvolvidas pelos professores visando a essa formação crítica.

Ao analisar os elementos mencionados pelos formadores como fundamentais para a formação inicial, existe pouca ou nenhuma referência a esse aspecto da formação crítica social.

Parece que a ideia do professor, quando mencionamos formação crítica, ainda é muito ligada, principalmente, à crítica de escolha de ferramentas tecnológicas, conteúdo matemático, textos ou elementos relacionados à melhor maneira de utilizar as tecnologias em sala de aula. Escolher criticamente cada um desses elementos é de suma importância; entretanto, segundo Corrêa (2000), Giroux (1997), Hargreaves (2004) e Kincheloe (1997), essa formação crítica está para além desses elementos citados pelos professores.

Os entrevistados mencionam o gerenciamento das informações veiculadas pelos meios de comunicação como parte da formação crítica do futuro professor. Nesse sentido, mencionam que o professor formador deve promover atividades em que seja necessário exercer julgamento acerca de informações veiculadas. Esta percepção está de acordo com o que aponta Ponte et al. (2000, p. 5): "[...] as tecnologias põem à disposição dos cidadãos uma massa extraordinária de informação, colocando à escola e aos professores o desafio de desenvolver nos jovens a capacidade de lidar de forma crítica e pertinente com esse importante recurso estratégico".

Percebe-se que, na perspectiva dos entrevistados, não é evidenciada uma forte preocupação ou mesmo o desenvolvimento de ações sólidas voltadas para a crítica social. Entretanto, tanto a Educação Matemática, por meio da linha de pesquisa referente à matemática crítica, quanto a Educação, indicam a necessidade de que essa dimensão seja explorada. As pesquisas em educação matemática crítica ressaltam a necessidade de que a educação matemática esteja engajada nos processos políticos e democráticos.

\section{Conclusão}

O desenvolvimento da presente pesquisa possibilitou uma discussão de como as novas tecnologias podem ser integradas à formação inicial do professor de matemática, além de possibilitar a compreensão de como o professor pode organizar sua prática, expor as dificuldades que o professor formador enfrenta no ensino via novas tecnologias e entender como sua prática de professor formador se aproxima da formação crítica dentro da perspectiva das tecnologias.

De modo geral, os formadores defendem que durante a formação inicial do professor de matemática haja contato com o maior número possível de ferramentas tecnológicas, assim como inferem que sejam destinados momentos para o estudo teórico e outros para o desenvolvimento de ações práticas relacionadas ao uso de tecnologias em sala de aula. Também é destacada a consolidação das disciplinas específicas da educação matemática para o trato das tecnologias como ferramenta para o ensino. 
Os entrevistados entendem que a tecnologia não é para embelezar a aula, mas deve ser uma ferramenta para construção de conhecimento da melhor maneira possível. Organizam a disciplina em momentos de estudos teóricos e momentos de atividades práticas, os quais têm o objetivo de levar o aluno da licenciatura a analisar e enxergar as ferramentas tecnológicas com um olhar analítico para identificar seus limites e possibilidades; desenvolver e aplicar roteiros de aulas; desenvolver atividades de investigação e resolução de problemas.

Dentre as dificuldades elencadas, temos a falta de laboratórios apropriados, as falhas de sistema, problemas de compatibilidade de arquivos e softwares, a falta de acesso às tecnologias, como computador e internet por parte dos alunos em suas residências. Com relação aos aspectos pedagógicos, foi mencionada a falta de interesse dos alunos pelo uso de tecnologias em sala de aula, a dificuldade para criação de roteiros e a falta de conhecimento específico por parte dos alunos.

Ficou evidente que ainda temos uma longa caminhada rumo a uma prática mais direcionada para a formação crítica. De maneira geral, os professores parecem desenvolver algum tipo de ação voltada para a formação crítica, mas essas ações ainda são mínimas e as reflexões críticas a respeito das questões sociais parecem não ser tão discutidas pelos formadores.

\section{Referências}

CORRÊA, V. Globalização e neoliberalismo: o que isso tem a ver com você professor? Rio de Janeiro: Quartet, 2000.

COSTA. N. M. L.; PRADO, M. E. B. B. A integração das tecnologias digitais ao ensino de matemática: desafio constante no cotidiano escolar do professor. Perspectivas da Educação Matemática, Campo Grande, v. 8, n. 6, p. 99-120, 2015. Disponível em: https://periodicos.ufms. br/index.php/pedmat/article/view/1392. Acesso em: 8 fev. 2021.

DINIZ-PEREIRA, J. E. A pesquisa dos educadores como estratégia para a construção de modelos críticos de formação docente. In: DINIZ-PEREIRA, J. E.; ZEICHNER, K. M. (org.). A pesquisa na formação de professores e no trabalho docente. 2. ed. Belo Horizonte: Autêntica, 2011. p. 2-20.

GIROUX, H. Os professores como intelectuais: rumo a uma pedagogia crítica da aprendizagem. Porto alegre: Artes Médicas, 1997.

HARGREAVES, A. O ensino na sociedade do conhecimento: educação na era da insegurança. Porto Alegre: Artmed, 2004.

JUSTICE, J. E.; TENORE, F. B. (ed.). Becoming critical teacher educators. New York: Routledge, 2018.

KINCHELOE, J. L. A formação do professor como compromisso social. Porto Alegre: Artes Médicas, 1997.

LEFÉVRE, F.; LEFÉVRE, A. M. C. O discurso do sujeito coletivo: um enfoque em pesquisa qualitativa (desdobramentos). 2. ed. Caxias do Sul: Educs, 2005.

LEFÉVRE, F.; LEFÉVRE, A. M. C. Pesquisa de representação social: um enfoque qualiquantitativo: a metodologia do discurso do sujeito coletivo. Brasília: Liber, 2010.

PHELAN, A.; SUMSION, J. (ed.). Critical readings in teacher education. Rotterdam: Sense, 2008. 
PONTE, J. P.; OLIVEIRA, H.; VARANDAS, J. M. As novas tecnologias na formação inicial de professores: análise de uma experiência. In: FERNANDES, M.; GONÇALVES, J. A.; BOLINA, M.; SALVADO, T.; VITORINO, T. (org.). O particular e o global no virar do milénio: actas do $5^{\circ}$ Congresso da Sociedade Portuguesa de Ciências da Educação. Lisboa: Edições Colibri: SPCE, 2002. p. 1-12.

PONTE, J. P.; JANUARIO, C.; FERREIRA, I. C.; CRUZ, I. Por uma formação inicial de professores de qualidade: documento de um grupo de trabalho do Conselho de Reitores das Universidades Portuguesas. [Lisboa]: CRUP, 2000. Disponível em: http://www.educ.fc.ul.pt/docentes/jponte/ artigos_pt.htm. Acesso em: 23 set. 2016.

ZEICHNER, K. A pesquisa-ação e a formação docente voltada para a justiça social: um estudo de caso dos Estados Unidos. In: DINIZ-PEREIRA, J. E.; ZEICHNER, K. M. (org.). A pesquisa na formação de professores e no trabalho docente. 2. ed. Belo Horizonte: Autêntica, 2011. p. 67-93. 